\title{
Macroeconomic Effects of Inflationary Shocks with Durable and Non-Durable Consumption
}

\author{
Sushanta K. Mallick ${ }^{1}$ • Mohammed Mohsin ${ }^{2}$
}

Published online: 28 June 2016

(C) The Author(s) 2016. This article is published with open access at Springerlink.com

\begin{abstract}
In this paper we show that inflation, both in the short and long run, negatively affects durable and non-durable consumption and output, and positively influences the current account balance. In particular, the impact of inflation is more pronounced on durable relative to non-durable goods. Using quarterly data from Canada, the UK and the USA, we demonstrate that these findings are consistent and robust across different econometric specifications. An open economy model with durable and non-durable consumption, households with labor/leisure choice and money introduced through cash-in-advance (CIA) constraint on consumption expenditure alone could meaningfully explain these empirical observations. Our empirical findings of non-neutral and negative effects of inflation on real growth are significant for many economic models in the asset pricing literature that support a negative co-movement of stock prices and expected inflation. Moreover, such positive inflation premium in our model could provide economic explanation for a positive slope of the nominal term structure in the data.
\end{abstract}

Keywords Durable goods · Current account · Sign VAR · Impulse responses

JEL Classifications $\mathrm{E} 52 \cdot \mathrm{E} 58 \cdot \mathrm{F} 32 \cdot \mathrm{F} 41$

Sushanta K. Mallick

s.k.mallick@qmul.ac.uk

Mohammed Mohsin

mmohsin@utk.edu

1 School of Business and Management, Queen Mary University of London, Mile End Road, London E1 4NS, UK

2 Department of Economics, University of Tennessee, 510 Stokely Management Center, Knoxville, TN 37996, USA 


\section{Introduction}

This paper evaluates the real effects of inflationary shocks in an economy at both theoretical and empirical levels. We address this issue from three directions. First, the paper provides empirical evidence from Canada, the UK and the US, that inflation negatively affects consumption (both durable and non-durable) and income, and positively influences the current account balance in each country. Our country selection is mainly based on availability of long high frequency time series data on aggregate durables and non-durables consumption. Using the standard correlation coefficients and estimating the impulse response functions from a structural vector error-correction (SVEC) model, we claim that these relationships are valid in the long run, except the current account balance which appears insignificant in case of Canada with a negative sign. Second, the paper attempts to provide a plausible theoretical explanation by augmenting a standard Ramsey type monetary growth model with durable and nondurable consumption that could potentially explain those empirical facts. Third, following Uhlig (2005), we further estimate impulse response functions by imposing sign restrictions as suggested in our simple model. The impulse response functions from the sign-restriction based structural VAR models in fact strengthen our initial empirical observations. Since a time-invariant VAR may not identify a possible regime shift (or an unconditional mean shift), we assessed the impact of unanticipated shocks by employing the time-varying SVAR methodology in Primiceri (2005). The results however remain consistent across different methods.

Using seasonally adjusted HP-filtered quarterly data, the correlation coefficient between US inflation and real consumption of durable and non-durable goods is found to be -0.29 and -0.21 respectively. Similarly, real output is negatively correlated with inflation with the estimated coefficient of -0.23 . The US real current account balance and inflation, on the contrary, are positively correlated with a coefficient of 0.34 . In the UK and Canada, we find similar correlation coefficients of -0.48 and -0.26 between inflation and durables respectively. For all other macro variables in Canada and the UK, the coefficients are in the similar vein. Correlation coefficients with lags ranging from 0 to 10 are good representations of short run effects. To trace the effects of inflation on any individual variable over the longer time horizon, we estimate the impulse response functions within a structural vector autoregressive setup. The estimates reveal that in the long run inflation negatively drives output and the consumption of durable and nondurable goods. Current account is positively affected by inflation in the long run. From the impulse response functions it is also clear that consumption of durable goods tends to be more sensitive than non-durable consumption to inflationary shocks during the early adjustment transitional period.

We propose a simple optimizing model of a small open economy that is consistent with these empirical phenomena. In our model economy, output is produced with a Ricardian production function. Output could be used as non-durable goods or could be transformed into durable goods with linear technology. The representative household can make labor-leisure decisions and consumes both durable and non-durable goods. We further assume that households face a cash-in-advance (CIA) constraint on their consumption expenditures. Under this setup it is shown that a higher inflation would lead to lower steady state level of consumption of both goods and the stock of durables. The reason is that with a CIA constraint on consumption expenditure, higher inflation 
increases the opportunity cost of holding real balances. This in fact will increase the relative price of both goods compared to leisure. Also, on impact, there is a very large substitution of leisure for consumption, and a substantial decrease in labor input. This decrease in labor will lower the long run output level in the economy. The net foreign asset position of the country will improve during the transitional period.

In addition, following Uhlig (2005), we have also estimated structural VAR models by imposing sign restrictions as obtained in our model. Imposing sign restrictions for model identification put the model for empirical validity. The estimated impulse response functions from these structural VAR models (including time-varying SVAR) are very much consistent with our initial claims.

The study is motivated by certain empirical observations and theoretical developments in the literature. Durables and semi-durables make up about $20 \%$ of total consumption expenditures in industrial countries, and durable goods are known to be a big part of the business cycles, yet most of the intertemporal optimizing (open economy) models incorporated mainly non-durable goods, and a few with only durable goods. Many researchers reported that durable goods exhibit initial excess volatility in response to monetary shocks. For example, De Gregorio, et al.(1998) pointed out that in Chile, Israel, Argentina expenditure on durable goods more than doubled from the beginning of the (stabilization) programme to the year in which consumption peaked, while total consumption increased by only $25 \%$ to $30 \%$. In the context of a closed economy, the excess volatility in durable consumption has also drawn significant attention among researchers. Especially it has been recognized that residential investment (including investment in other consumer durables) leads investment over the business cycle. Though it is well documented that these two sectors comove positively over the business cycle, ${ }^{1}$ real business cycle $(\mathrm{RBC})$ researchers are often less successful to account for the different investment dynamics. With vector autoregression (VAR) analysis, Erceg and Levin (2006) documented the effects of external shocks across the two sectors of the economy. In US quarterly data, they found that the durable goods sector is much more interest-sensitive (roughly five times as large) than the non-durable sector. We also intend to examine this sector specific sensitivity following inflationary shocks in a small open economy framework.

The introduction of durable goods in a standard optimizing framework allows for a more realistic evaluation of the effects of monetary policies. In the asset pricing literature, the important references include Dunn and Singleton (1986), Ferson and Constantinides (1991) and Heaton (1995). Mankiw (1987) incorporates consumer durables along with non-durables in the neoclassical growth model in an attempt to examine the dynamic impacts of fiscal policies on real interest rates in a closed economy setup. Interestingly, there is no significant attempt in the open economy macroeconomic literature that offers an optimizing model with both durable and nondurable consumption to examine the implications of monetary policies. This paper intends to fill these gaps.

Our finding have other interesting implications as well. The non-neutral and negative effects of inflation on real growth are cornerstones in many economic models in the asset pricing literature that propose a negative co-movement of stock prices and expected inflation. A negative response of long-run real growth to inflation produces

\footnotetext{
${ }^{1}$ For details see Fisher (2001).
} 
positive inflation premium. This makes long-term nominal bonds risky, and is viewed as one of the leading economic explanations for a positive slope of the nominal term structure in the data. See e.g. Piazzesi and Schneider (2006), Hasseltoft (2012), Bansal and Shaliastovich (2013) and others who provide empirical evidence for this channel for a single non-durable consumption good. Recently, Eraker, Shaliastovich, and Wang (2014) extended the literature in the context of durable consumption as well. They also showed that the negative correlation between inflation and consumption is highly pronounced when consumption goods exhibit durability. ${ }^{2}$ Though, these papers focus exclusively on asset prices, which is different from this study, our findings seem very useful.

The paper is organized as follows. Our empirical findings are documented in section 2. Section 3 develops an open economy model to explain the empirics. In section 4 we evaluate the empirical validity of our model through the sign VAR approach as proposed by Uhlig (2005) and the time-varying SVAR due to Primiceri (2005), followed by concluding remarks in Section 5 .

\section{Empirical Observations}

One of the major objectives of this study is to examine the real effects of inflation at the empirical level on key macroeconomic variables, namely consumption of durable and non-durable goods, output and the current account balance of open economies. We are using data from three economies - the United States [1960:Q1 to 2004:Q4], the United Kingdom [1963:Q1 to 2004:Q4] and Canada [1961:Q1 to 2004:Q4]. The quarterly series used in this study are seasonally adjusted observations on real durable consumers' expenditure, real non-durable consumers' expenditure, consumer price index, real GDP, and real current account balance. ${ }^{3}$ All the series are compiled from the respective national sources within the Datastream database. The sources for real durables and real non-durables are the 'National Income and Product Account' (NIPA) for the US, the 'Office for National Statistics' for the UK and 'Statistics Canada' for Canada. For the UK and Canada, 'durables' refer to series calculated using both durables and semi-durables, since the official definition of semi-durables includes items such as furnishings, which are typically considered durable in an economic sense.

The natural logarithms of durables, non-durables and GDP (all expressed in real terms) are denoted as LDUR, LNDUR, and LGDP. Inflation (INF) is calculated as fourth lag difference of $\log$ CPI. To express the nominal current account balance in real terms (CA), we used the average of the national accounts deflators for exports and

\footnotetext{
${ }^{2}$ In Yang (2011), the growth rates of durable goods are much more persistent than the growth rates of nondurable goods. In our model, larger immediate effects on durables are due to household's ability to exercise inter-temporal substitution. Any given time, there is a stock of consumer durables. This allows the household to postpone (or lower) current purchases of durable goods that just became more expensive due to higher inflation following policy shocks.

${ }^{3}$ Instead of GDP, we could have used employment data. In our model, as we will see later, output is produced with labor only. For empirical purpose, we could have used any one of these series to capture this effect. We decided to use GDP for many practical reasons. For example, it is well known that employment and output data are highly correlated. But, survey based employment data is known to contain significant noise. Moreover, GDP data in our sample countries are significantly reliable.
} 
imports of goods and services to convert the nominal current account balance for the US and the UK, whereas for Canada, we derived the respective deflators from data for the exports and imports of goods and services (nominal and real), then averaged the two in order to deflate the nominal current account balance. As current account contains negative values for many years for all the three countries, we expressed the series in levels without logs.

First we examine the cross correlations up to 10 lags between LDUR, LNDUR, $\mathrm{CAB}$, LGDP, and inflation. Results are reported in Fig. 1a-c. Before doing so we smooth all the data series through the Hodrick-Prescott (HP) filter using the conventional filter weight of 1600.The HP filter separates the cyclical behavior from the long run path of the economic series. The benefit of the HP decomposition is that it uses a uniform method to extract the long run component from a set of variables. The correlations for the three countries are calculated with the smoothed series using the HP filter. In each country the durables expenditure has a higher negative correlation with inflation relative to non-durables. Current account behavior, however, differs between the three countries. As Canada had a current account deficit during most part of the sample period and it is only since 1998 that Canada has been experiencing a surplus, the correlations tend to indicate a smaller deterioration in the current account with higher order lags. In the US and the UK, the correlation between the current account and inflation has been positive and slowing down.

We also consider a fiscal variable namely real government expenditure (LGEX) to disentangle fiscal surprises from monetary sources of inflationary shocks. We find all these time series to have different order of integration under different test assumptions for the three countries, as indicated by the results of Augmented Dickey-Fuller (ADF) and other tests. Current account series turned out to be stationary or I(0) in the case of the UK and Canada, but non-stationary in the US. In the context of Canada, Iscan (2002) also finds that Canada's current account balance is stationary in levels. The results of the unit root tests ${ }^{4}$ are presented in Table 1 . Allowing for a single structural break in the level and trend of each series, we follow the procedure of Zivot and Andrews (1992), in order to estimate the breakpoint from the data. Inflation in the US and Canada turns out to be stationary when applying the ZA test with break. Government expenditure in the UKis also stationary, while all other variables are nonstationary with a break-point prior to the early 1990s. The tests show that the time series properties of the variables do not suggest the variables being I(2) for any of these countries. Thus we undertake the Johansen's (1988) cointegration test to check whether we need to carry out an unrestricted or cointegrated VAR exercise for these three countries. Further, despite the current account balance in the UK and Canada being stationary or I(0) suggested by the DFGLS test, and inflation being stationary in the US as suggested by the KFSS test, we have undertaken the cointegration tests for the three countries and find that there is cointegration among the variables, given unit root in most of the variables. This leads us to estimate a structural vector error correction model (SVECM) with1 lag as found to be optimal by most lag selection test criteria.

\footnotetext{
${ }^{4}$ The ADF test suggests that the six variables for the US are stationary in first differences, which means the series in levels are I(1), while the KPSS test suggests that inflation in the US is stationary. In Table 1, we have reported the tests for the variables in levels, not the tests for variables in first differences, which are available from the authors upon request.
} 
a Cross correlations with inflation for the US
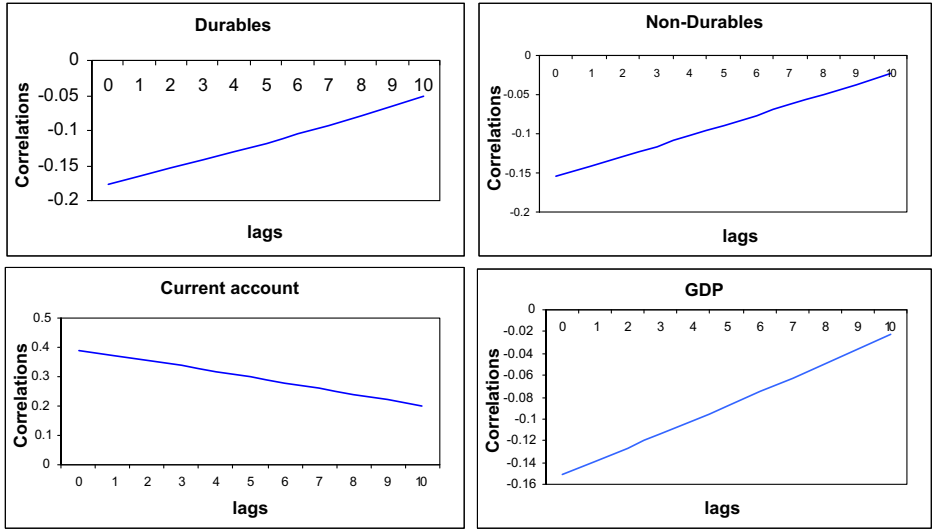

b Cross correlations with inflation for the UK
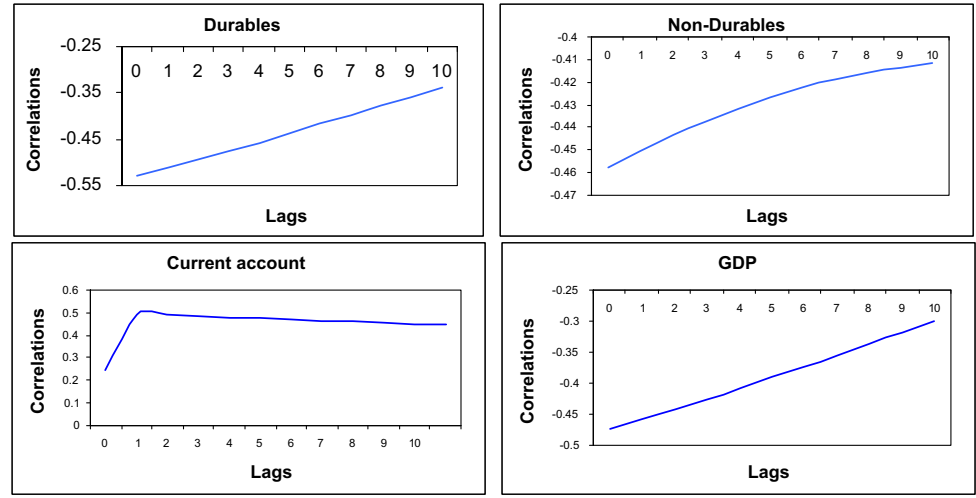

\section{Cross correlations with inflation for Canada}
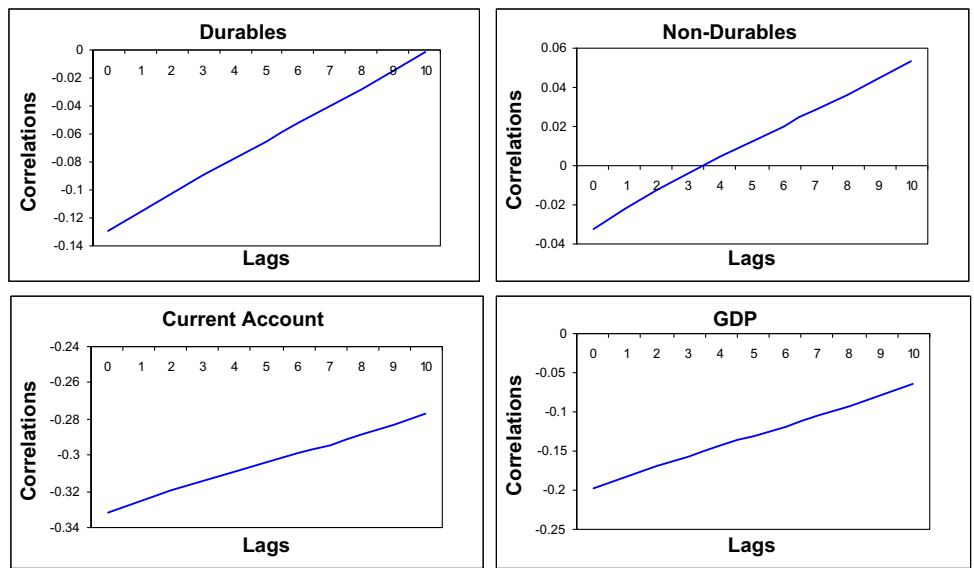

Fig. 1 a Cross correlations with inflation for the US. b Cross correlations with inflation for the UK. c Cross correlations with inflation for Canada 
Table 1 Testing for Unit Roots

USA

\begin{tabular}{lllllll}
\hline & $A D F\left(t_{\alpha c}\right)$ & $A D F\left(t_{\alpha c t}\right)$ & $D F G L S$ & $K P S S$ & $Z A$ & \\
$D U R$ & 0.0177 & -2.1925 & 4.3623 & $1.7034^{*}$ & -3.8007 & {$[1990: 02]$} \\
$N D U R$ & 0.1170 & -1.8172 & 2.6110 & $1.7238^{*}$ & -3.5467 & {$[1990: 02]$} \\
CA & 3.8860 & 1.7686 & 4.6217 & $1.1692^{*}$ & -3.4529 & {$[1995: 01]$} \\
$G D P$ & -1.2167 & $-3.5693 *$ & 2.6518 & $1.7286^{*}$ & -4.4144 & {$[1973: 03]$} \\
INF & -1.8438 & -2.0849 & -1.1892 & 0.3303 & $-7.7182^{* *}$ & {$[1981: 04]$} \\
LGEX & -1.6525 & -2.6233 & 1.515 & $3.5270^{* *}$ & -3.8785 & {$[1967: 03]$}
\end{tabular}

UK

\begin{tabular}{lllllll} 
DUR & 1.4073 & -1.7137 & 4.5456 & $1.5962^{*}$ & -3.3108 & {$[1990: 03]$} \\
NDUR & -2.2119 & $-5.1439^{*}$ & 2.3907 & $1.6141^{*}$ & -3.7629 & {$[1986: 01]$} \\
CA & -2.4001 & $-3.4639^{* *}$ & $-1.7506^{*}$ & $0.9196^{*}$ & -3.2259 & {$[1986: 02]$} \\
$G D P$ & -0.7279 & -2.6803 & 5.7070 & $1.6174^{*}$ & -4.4673 & {$[1979: 03]$} \\
$I N F$ & -1.3061 & -2.3026 & -0.9253 & $0.5481^{*}$ & -4.7411 & {$[1980: 03]$} \\
LGEX & $-8.0667 * *$ & $-8.8097^{* *}$ & $-8.034^{* *}$ & $1.9524^{* *}$ & $-5.6314 * *$ & {$[1992: 03]$} \\
CANADA & & & & & \\
DUR & -2.1208 & -2.0903 & 1.9115 & $1.6296^{*}$ & -4.1151 & {$[1971: 02]$} \\
$N D U R$ & $-3.7503 * *$ & -2.6733 & 1.0776 & $1.5558^{*}$ & -3.8042 & {$[1970: 03]$} \\
CA & -1.8247 & -2.0843 & $-1.8758^{*}$ & 0.3269 & -4.8558 & {$[1989: 01]$} \\
$G D P$ & $-2.7760^{*}$ & -2.7463 & 2.1162 & $1.8298^{*}$ & -3.7529 & {$[1971: 02]$} \\
$I N F$ & -1.9822 & -2.3785 & -0.9872 & $0.4888^{*}$ & $-5.2337 *$ & {$[1983: 01]$} \\
$L G E X$ & $-4.296^{* *}$ & 0.3137 & 4.245 & $3.4586^{* *}$ & -2.5036 & {$[1982: 02]$} \\
\hline
\end{tabular}

1. $A D F\left(t_{\alpha c}\right)$ and $A D F\left(t_{\alpha c t}\right)$ are the test statistics on the lagged variable in the Augmented Dickey-Fuller test regression with constant, and constant and time trend respectively. DFGLS and KPSS tests are known as Dickey-Fuller test with GLS detrending, and the Kwiatkowski, Phillips, Schmidt, and Shin test respectively. The DFGLS test involves estimating the standard ADF test equation with the GLS detrended data as opposed to the original series. The KPSS test differs from other unit root tests in the sense that the time series is assumed to be trend-stationary under the null. The optimal lag length in the ADF test is 1, which has been automatically selected by the lag selection criteria.Zivot-Andrews (ZA) test allows for structural break in intercept.

2. $*$ and $* *$ denote rejection of the null at $10 \%$ and $5 \%$ level of significance respectively. The asymptotic $10 \%$ critical values are: ADF test: -2.5754 (with constant) -3.1416 (with constant and trend); DFGLS: -1.6155 (with constant); KPSS: 0.3470 (with constant). Under KPSS test, the null is stationary. ZA Critical Values are -5.57 and -5.08 for $1 \%$ and $5 \%$ respectively. Numbers in brackets are the estimated structural breaks based on the ZA test

The SVECM has been used to carry out the shock analysis by applying recursive ordering of variables in order to identify the shocks. We specify the following ordering in order to structurally identify the two key shocks (fiscal and non-fiscal sources of inflationary shocks): [LGEX, INF, LNDUR, LDUR, LGDP, CAB]. The reason behind this specific recursive ordering stems from the theoretical ordering of the variables that should run from the more exogenous to the less exogenous variable. The VECM methodology with a recursive identification approach allows us to tell a structural story; namely fiscal and other inflationary shocks drive inflation which then causes certain responses in other 
endogenous variables. Thus inflation is ordered first, followed by consumption, output and current account balance. Even if an alternative ordering of the endogenous variables is used, the results however remain less sensitive. The detailed econometric methodology for the impulse response analysis is not discussed here for the sake of brevity.

Our aim here is to track the response of durables, non-durables, current account and GDP to inflation shocks, alongside the response of fiscal shocks. As mentioned earlier, we have carried out the VECMs for each country with 1 lag, as a VECM includes first differenced series. On the basis of different lag order selection criteria, we found two lags to be the optimum lag length for the VAR by FPE (Final prediction error), AIC (Akaike information criterion) and HQ (Hannan-Quinn information criterion), whereas SC (Schwarz information criterion) suggests 1 lag, and LR (sequential modified LR test statistic) suggests 3 lags as the optimal lag. Whether we estimate a VAR with 2 or 3 lags, there is little difference in the impulse responses. The estimated coefficients are not presented here. Instead we have shown the results obtained from the VECM models through the impulse response functions (IRFs) as displayed in the Figs. 2, 3, and 4. Since the variables are defined in terms of first-differenced series in a VEC model, it is customary to plot cumulative impulse response functions that can help us examine the steady state (long run) effects.

Impulse response analysis shows how the above endogenous variables in the model react to the inflation disturbances using the Structural VEC model for the US, the UK and Canada. We plot the estimated response coefficients up to a forecast horizon of 20 quarters (or 5 years). For each country, there are five figures: inflation, non-durables, durables, GDP and the current account. The responses are expressed as deviations from the base values following a positive shock to government expenditure and inflation residuals. In other words, the impulse response functions in Figs. 2, 3, and 4 display the expected cumulative changes in the endogenous variables following a shock to government expenditure and inflation disturbances. The dashed curves represent the confidence interval around the estimated response functions, computed from a typical Monte Carlo integration exercise with 1000 replications.

The exact magnitude of the inflationary impact is revealed when we carry out the shock analysis using the model. In the long run, we find that there is a negative significant relation between durables consumption and inflation, and this response is higher in the case of durables than in the non-durables, which proves our hypothesis. This result jibes well with the finding of Madsen (2001), which uses a mean-variance model of portfolio selection and finds that demand for durables is significantly adversely affected by inflation using quarterly data for the USA and annual panel data for the OECD countries. We find that the durable demand is more sensitive than the nondurable demand to inflation shocks, ${ }^{5}$ and the current account is initially in deficit and then reacting in an opposite direction, as durable demand continues to decline. In the context of the theoretical model to be discussed below, the rise in inflation directly reduces real money balances, creating a negative wealth effect; indirectly the negative income effect could dominate the intertemporal substitution effect thereby reducing

\footnotetext{
${ }^{5}$ It is possible that this sensitivity could be due to higher demand elasticity of durables vs. non-durables (say, cars vs. food). We are unable to take out the inelastic demand items due to data unavailability of different components of these two broad categories.
} 

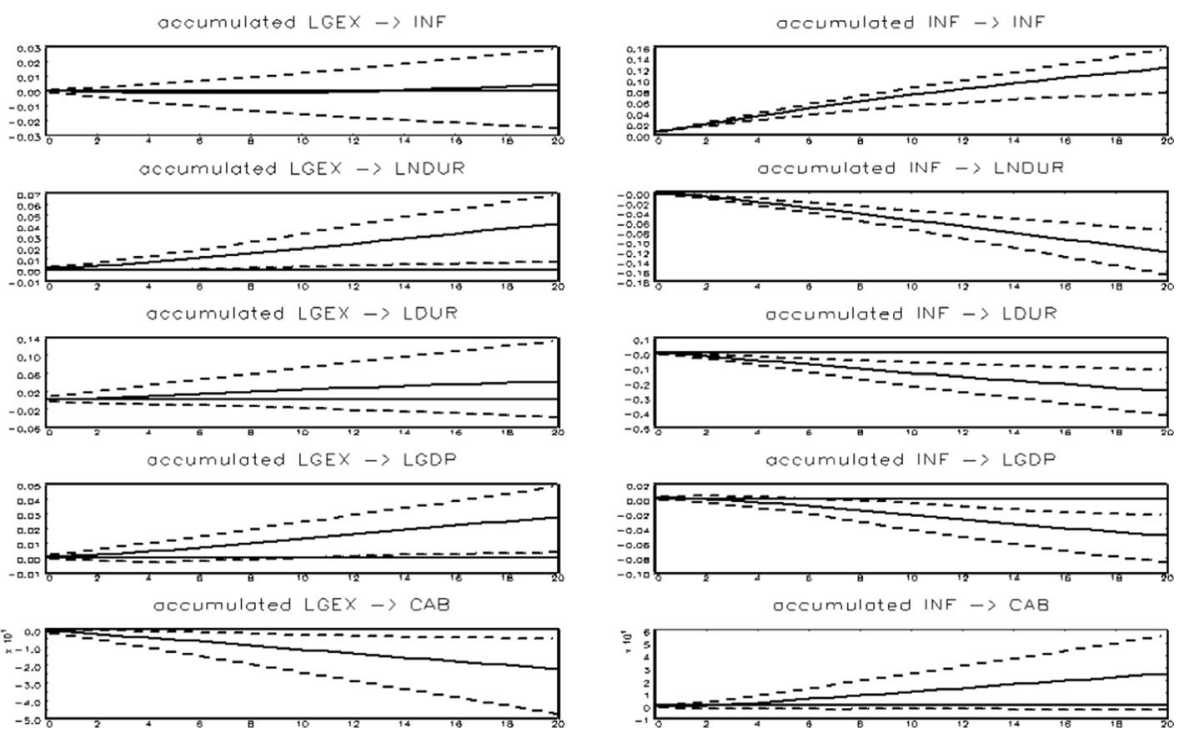

accumulated INF $\rightarrow$ LDUR
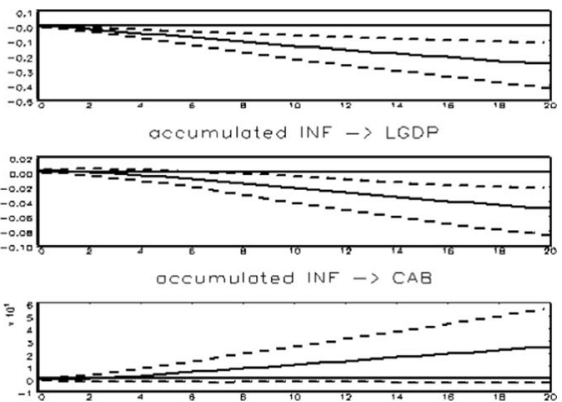

Fig. 2 US: SVEC Impulse Responses to Fiscal and other Inflationary Shocks

households' income and consumption. This initial response in consumption gradually converges to a higher steady state level.

For the US, the decline in durable goods due to inflation shocks continues to the extent of $10 \%$, whereas non-durable goods only decline to the extent of $5 \%$ (see Fig. 2). The opposite is the case with respect to the current account response (see Fig. 2 (bottom panel)). As the current account balance is expressed in levels, the regression coefficients or impulse responses need to be interpreted in terms of billions. With a $1 \%$

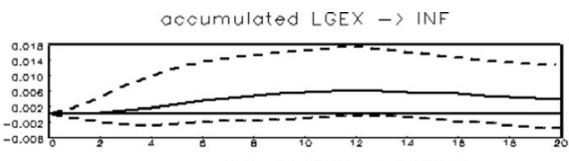

accumulated LGEX $\rightarrow$ LNDUR

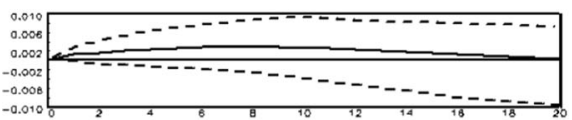

accumulated LGEX $\rightarrow$ LDUR

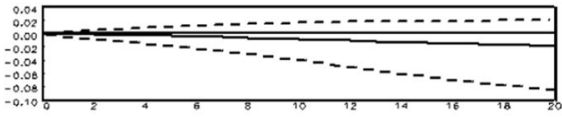

occumulated LGEX $\rightarrow$ LGDP

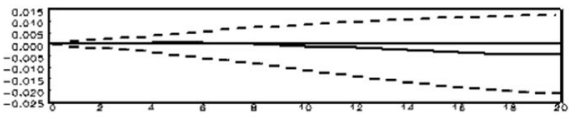

acoumulated LGEX $\rightarrow$ CAB

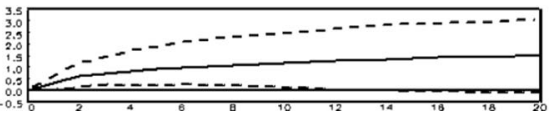

accumulated INF $\rightarrow$ INF

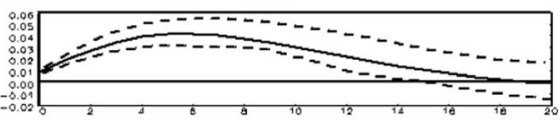

occumulated INF $\rightarrow$ LNDUR

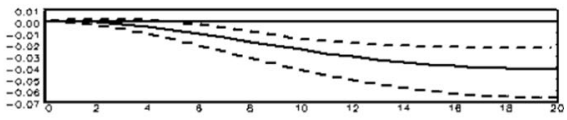

occumuloted INF -> LDUR

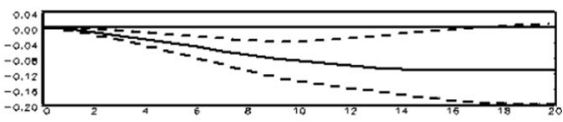

accumulated INF $\rightarrow$ LGDP

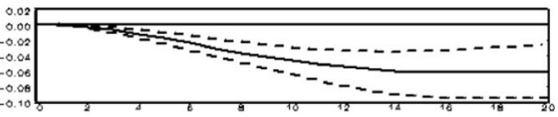

occumulated INF $\rightarrow$ CAB

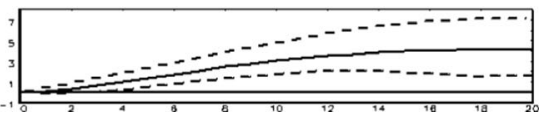

Fig. 3 UK: SVEC Impulse Responses to Fiscal and other Inflationary shocks 

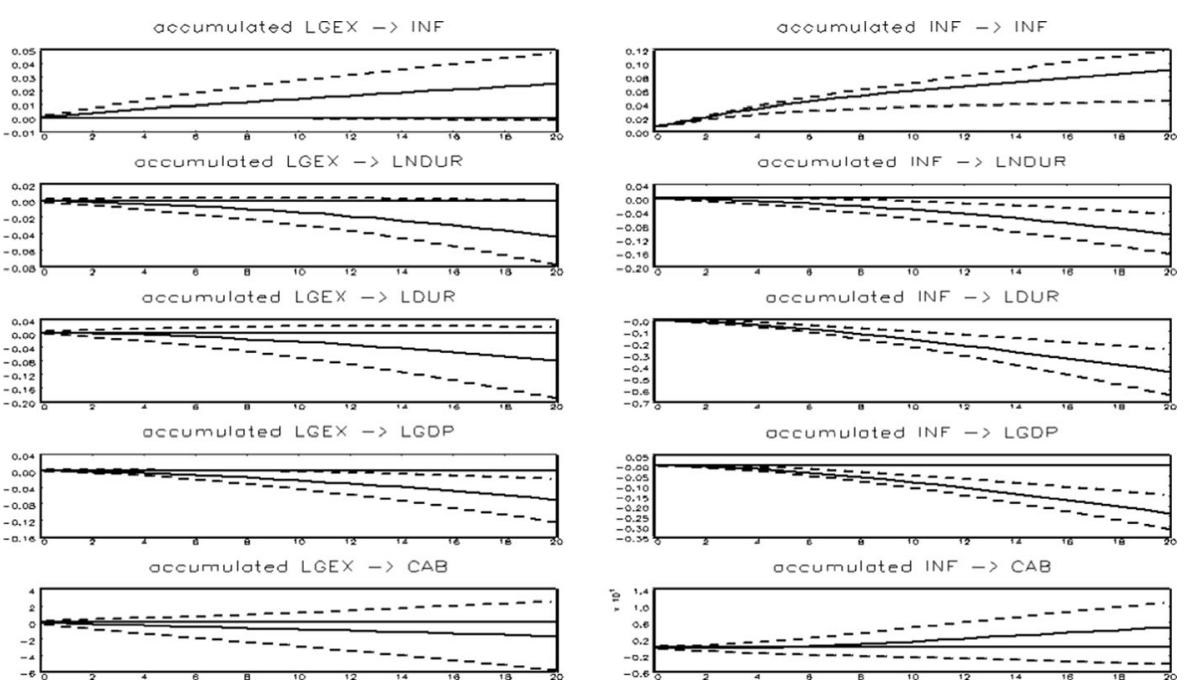

accumulated INF $\rightarrow$ LNDUR

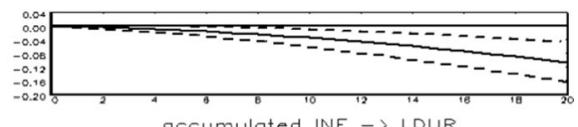

occumulated INF $\rightarrow$ LDUR

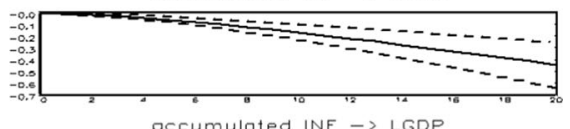

accumulated INF $\rightarrow$ LGDP

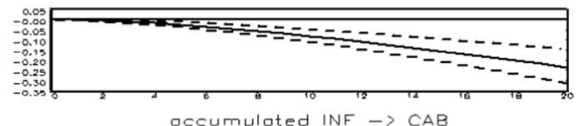

accumuloted INF $\rightarrow$ CAB

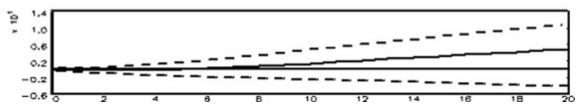

Fig. 4 Canada: SVEC Impulse Responses to Fiscal and other Inflationary shocks

inflation shock, the current account improves to a long-run surplus of around US\$2 billion a quarter. The link between durables (non-durables) and the current account needs to be understood via the intertemporal saving channel. Following an inflation shock in the US, durable consumption declines, implying a rise in savings and thus an improvement in the current account balance, whereas on the other hand, as durable consumption declines, income also goes down and hence saving could fall. From Fig. 2, the net effect appears to be an increase in savings, which gets reflected in external asset holdings, leading initially to a decline in the current account balance that improves in the long-run until it converges to the steady state.

Similarly for the UK, as shown in Fig. 3, although the direction of the durable goods response remains the same, the magnitude of the impact is less compared to the US. The current account on the other hand improves to a steady state level of around $£ 3.0$ billion in a cumulative sense (see Fig. 3 (bottom panel)). For Canada (Fig. 4), durable goods consumption declines, but the current account remains in deficit or near zero in the long-run. For Canada the current account dynamics have been volatile, whereas this response has been smooth for the UK and the US. Nevertheless, the non-monotonic behavior of the current account has been evident in all the three countries. The current account response however does not appear to be significant in the US and Canada, suggesting that the current account balance can be zero in the long run.

By and large, the Figs 2, 3, and 4 reveal that there is an overreaction of durable goods consumption and the magnitude of the impact on durables is large relative to non-durables for all the three countries. Interestingly, the excess-reaction in durable consumption is more pronounced than the GDP response, which is more in line with the behavior of non-durables consumption. This is intuitive as non-durables account for big part of the GDP. Besides, we do find evidence to suggest that positive government expenditure shocks can generate inflationary shocks as in the case of the UK and Canada, but not in the US. This means that inflationary shocks in the US appear to be driven by monetary variables. It is also evident that when fiscal shocks generate inflationary pressures, they tend to have negative effect on real output (see the case 
of Canada in Fig. 4). For the US however, fiscal spending shock has a positive impact on output with no inflationary impact (see Fig. 2), while for the UK the government spending shock has a neutral effect on GDP (see Fig. 3).

We have also carried out variance decomposition analysis to identify the contribution of inflation shock to the real variables considered here. We decompose variation in the percentage change of the forecast error variance of durables, non-durables, GDP and the current account that are due to a shock in each variable along with inflation shocks at the 1-40-quarter horizons. The results suggest that inflation shocks are found to account for about $20 \%$ of the variability of the real variables over a long timehorizon. Although their own shocks account for big part of the variability, they tend to die out in the long run.

\section{A Possible Theoretical Explanation}

The model structure we suggest here is that of a small open economy and has much in common with Mallick and Mohsin (2010) with significant differences. ${ }^{6}$ In terms of similarities both models deal with small open economy with two goods - durable and non-durable and study the real effects of inflationary shocks. As a result, certain modeling features have common threads. However, the differences are significant as well. For example, in Mallick and Mohsin (2010), output is procured with capital only and investment plays a significant role in that economy. This is particularly important as one wants to study the current account dynamics. We all know, current account dynamics are heavily influenced by the presence (or absence) of capital accumulation. Moreover, with inelastic labor supply, households have no labor/leisure choice. This is also an important ingredient in a dynamic model where a-temporal and inter-temporal substitution play significant role. In that model both households and firms are subject to cash-in-advance requirements. In this paper, as we will see gradually, we have a simple Ricardian production structure. Such a simple production structure is purposely adopted as we want to investigate the channel controlled by labor leisure choice. The household's preferences are very robust in this version. Also, as we abstract from investment, only households are subject to CIA requirement in this model. It is well established in the monetary growth literature that the effects of monetary policies are very sensitive to various CIA constraints (see Stockman (1981) and Able (1985)). In other words, these differences are significant indeed. All these modifications will allow us to provide a theoretical explanation and a basis for further empirical investigation that we report in the following section. Also, there are differences with regard to empirical methodologies employed in this paper by estimating structural VECM, sign VAR and time-varying SVAR models. Besides, in the empirical part of this paper, we identify a fiscal shock which was not done in Mallick and Mohsin (2010).

\footnotetext{
${ }^{6}$ Both this paper and Mallick and Mohsin (2010) are improved from Mohsin (2006). It is important to note that Mohsin (2006) is a one good model aimed at studying the effects of fiscal policies. Here, we have two goods - durable and non-durable. With two goods, it allows us to compare and contrast the dynamics of consumption of durables vis-à-vis non-durables in an economy following various policy shocks. To study the effects of monetary policy, we introduce money into the model. There are significant differences in production structure as well.
} 
We briefly discuss the core theoretical model, avoiding the technical details here. Output $Y$ is produced with labor as the only input:

$$
Y_{t}=1-l_{t},
$$

where $1-l_{t}\left(\equiv L_{t}\right)$ is employment at time $t$, assuming that at any instance one unit of time is available to the representative agent of which he consumes $l_{t}$ as leisure. The foreign currency price per unit of output is $P^{*}$, which the small economy takes as given. The domestic-currency price is $P=E P^{*}$, where $E$ is the exchange rate (the price of the foreign currency in terms of the domestic currency). With flexible goods prices, the rate of inflation is equal to the rate of depreciation of the domestic currency $\left(E_{t} / E_{t}\right)$, which is denoted by $\varepsilon_{t}$. Output is used as non-durable goods. The agent could also convert a portion of output into durable goods following a linear technology. ${ }^{7}$

The objective of the representative household is to maximize

$$
\int_{0}^{\infty} e^{-\beta t} u\left(d_{t}+s_{t}, c_{t}, l_{t}\right) d t
$$

where $\beta$ is the fixed rate of time preference. The instantaneous utility function depends on the current consumption of the services of consumer durables $\left(d_{t}+s_{\mathrm{t}}\right)$ and nondurables $\left(c_{t}\right)$, and leisure $\left(l_{t}\right)$. For simplicity we assume that $u(d+s, c, l)=U(d+s, c)+$ $V(l)$. Note that $d_{t}$ is the amount of consumer durables purchased at time $t$, while $s_{t}$ is the stock of durables, which are inherited from the past. These durable goods depreciate at the rate of $\delta$. Hence, the evolution of $s_{\mathrm{t}}$ is given by

$$
\dot{s} s_{t}=d_{t}-\delta s_{t}
$$

Note that $d_{t}$ is the amount of consumer durables purchased at time $t$, while $s_{t}$ is the stock of durables, which are inherited from the past. Money is introduced through a CIA constraint:

$$
m_{t} \geq \alpha\left(c_{t}+d_{t}\right)
$$

which requires that at any point in time the representative household should hold enough real money balances $m_{t}$ in order to finance $\alpha$ proportion of his/her total consumption purchases. Apart from the stock of durable goods, there are two kinds of assets in this model: real money balances $\left(m_{t}\right)$, and the stock of internationally traded

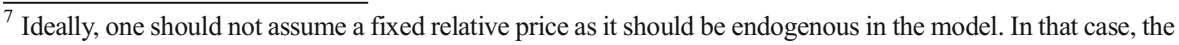
relative price will adjust as the relative demand for two goods changes due to external policy shocks. Since both durable and non-durable goods are subject to similar cash-in-advance requirements (see equation (4)), the fixed relative price assumption will not distort the main results of the model by a lot. Since higher inflation affects both goods (a key source of external shock), the immediate short run effect will be similar even after allowing for endogenous relative price. Of course, the "relative price effect" will be evident after the initial adjustment. Our results are consistent with many empirical studies that claim the demand for durable goods to decline significantly (compared to non-durables) due to higher inflation even when they allow the relative price to adjust in the economy. Admittedly, this is a limitation we purposely adopted to simplify our model. This assumption is consistent with Mankiw (1987) as well. However, since we have a fixed relative price, our model should be considered as a partial equilibrium (instead of general equilibrium) open economy model.
} 
bonds $(b)$ whose foreign currency price is fixed, and which have a fixed rate of return of $r$. The real assets of the household at any point in time $t$ is the sum of real balances and foreign bonds: $a_{t}=m_{t}+b_{t}$. The representative household receives real monetary transfers of $\tau_{t}$ from the government and pays $T_{t}$ as lump sum taxes. Hence, his flow budget constraint is

$$
\dot{a}_{t}=w_{t}\left(1-l_{t}\right)+r b_{t}+\tau_{t}-c_{t}-d_{t}-T_{t}-\varepsilon_{t} m_{t}
$$

where $w_{t}$ represents the real wage at time $t$. The representative household's problem is to maximize (2), subject to (3), (4), (5), and the initial conditions $\left(a_{0}, s_{0}\right)$. Moreover, as money does not yield direct utility, and bonds dominate real balances in terms of return, (4) will hold with strict equality as long as the nominal interest rate is positive. A detailed solution is avoided here, but will be made available upon request.

To keep our model simple we assume that the government has no outstanding bonds or debt. The government satisfies the following flow budget constraint:

$$
\dot{m}_{t}+\varepsilon_{t} m_{t}+T_{t}=\tau_{t}+g_{t}
$$

according to which total government real expenditure (real transfer $\tau_{t}$ plus government expenditure on goods and services $g_{t}$ ) should be equal to total government revenues from seigniorage $\left(m_{t}+\varepsilon_{t} m_{t}\right)$ and lump sum taxes $T_{t}$. We also assume that the central bank controls the domestic inflation rate $\varepsilon$ by adjusting $\tau$ continuously. This approach is consistent with Calvo (1987), Calvo and Vegh (1995), Mishkin (2000) and Mansoorian and Mohsin (2006). ${ }^{8}$ This will be easier to understand if we assume (for the sake of clarity) that $g_{t}=T_{t}$. In that setting equation (6) is reduced to: $m_{t}+\varepsilon_{t} m_{t}=\tau_{t}$. Now given the real balances (as residually determined by consumption of durables and nondurables; see equation (4)) the central bank can fix the desired level of inflation to match the real value of $\tau$. We should note that both durable and non-durable consumption are directly and indirectly affected by inflationary shocks. As a result, output and current account balance are also affected. The following propositions will summarize the main results. ${ }^{9}$

Proposition 1: In the steady state, a permanently higher inflation (or government expenditure) will cause the economy to have lower demand for both durable and non-durable consumption. Output level decreases in the economy. While the stock of durables goes down, the economy improves in terms of net foreign assets.

\footnotetext{
${ }^{8}$ The conventional approach in monetary growth literature is to in introduce the growth rate of money supply to study the effects of monetary policy. In that setting inflation is endogenously determined. In examining the detailed transitional dynamics, one must account for the equation that explains the growth rate of money supply. Obviously, it will increase the dimension of the dynamic system and as a result, getting analytical solution in terms of long run and transitional effects are cumbersome (if not undoable). Without getting into the debate whether inflation is endogenous or not, our assumption of controlling inflation is technical in nature. Of course one must understand that in a model with no population growth and no long run growth (the model in this study), it could be easily shown that the rate of growth of money supply and the inflation rate are identical in the steady state. Moreover, the literature concerned with the time consistency of monetary policies (e.g., Kydland and Prescott (1977), Backus and Driffill (1985), and Walsh (1995)), also assumes that the central bank targets the inflation rate (not the rate of growth of money per se).

9 The analytical results are provided in Appendix I.
} 
Proposition 2: In response to higher inflation (or government expenditure), on impact, both durable and nondurable consumption declines. Durable consumption 'overshoots'. Net foreign asset position does not change in the short run.

The results are very intuitive too. With a CIA constraint on consumption expenditure, higher inflation increases the relative price of both goods compared to leisure. As a result, we observe lower demand for both the goods and higher demand for leisure. Higher leisure also implies decrease in labor supply and hence labor input in the production process. This decrease in labor will decrease the long run level of output in the economy. The current account improves during the transitional period. To explain this we need to draw our attention to the equation that denotes the net savings of the economy. If we incorporate the budget constraint of the households and the government and incorporate the fact $a_{t}=m_{t}+b_{t}$ (and hence $a_{t}=m_{t}+b_{t}$ ) we get the following equation that captures the current account balance of the economy (net change in foreign asset position):

$$
\dot{b}_{t}=Y_{t}+r b_{t}-d_{t}-c_{t}-g_{t} .
$$

It is very clear from the above equation that the current account balance of the economy depends on total income $\left(Y_{t}+r b_{t}\right)$ and total absorption $\left(c_{t}+d_{t}+g_{t}\right)$. So, any increase (or decrease) in output (keeping everything else unchanged), will improve (or worsen) the net asset position of the economy. Similarly, any increase (or decrease) in absorption (through consumption of both types of goods or government expenditure) will decrease (or improve) the current account balance of the economy. In this model the current account improves during the transitional period as decrease in consumption level dominates the decrease in output. Moreover, we could also argue that to accommodate the increasing consumption of durable goods during the transitional period, the households must be saving by buying foreign bonds. Also, the short-run overshooting of durable spending, following inflationary shock, is shown in the appendix in detail.

\section{Further Empirics: Robustness Checks}

\subsection{Sign Restriction Approach}

In order to further validate the results from traditional SVAR modeling as well as to evaluate the proposed model, we undertake a 'pure sign restriction' identification strategy due to Uhlig (2005). A brief discussion of the methodology is warranted here. Unlike the traditional VAR approach, in order to completely identify the system, Uhlig (2005) proposed imposing sign restrictions on the impulse response functions. We outline below the key steps in the sign identification procedure starting with a VAR as follows: $Y_{t}=\sum_{i=1}^{l} B_{i} Y_{t-i}+u_{t}, t=1, \ldots, T$

where $Y_{t}$ is a $n \times 1$ vector, $l$ is the lag length of the VAR, $B_{i}$ are coefficient matrices of size $n \times n$ and finally, $u_{t}$ is the one-step ahead prediction error with variancecovariance matrix $\Sigma$. After having estimated the reduced form VAR model, in the 


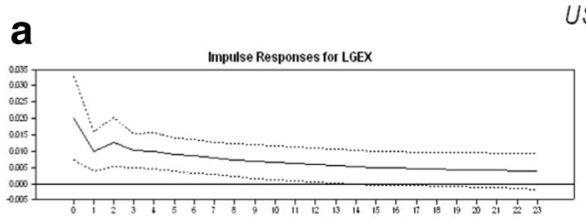

USA
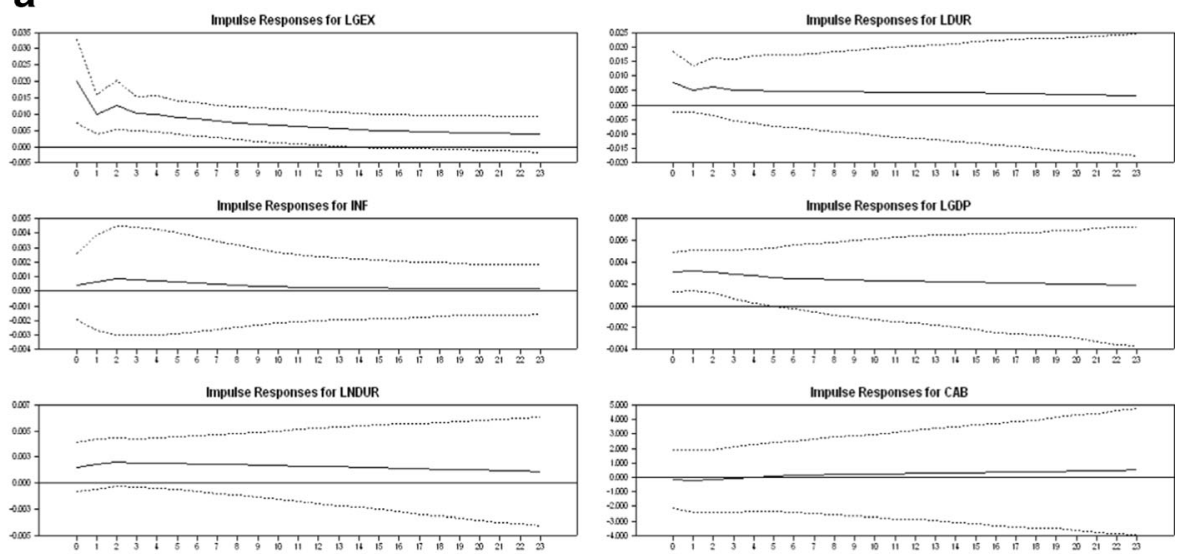

Impulse Responses with Pure-Sign Approach

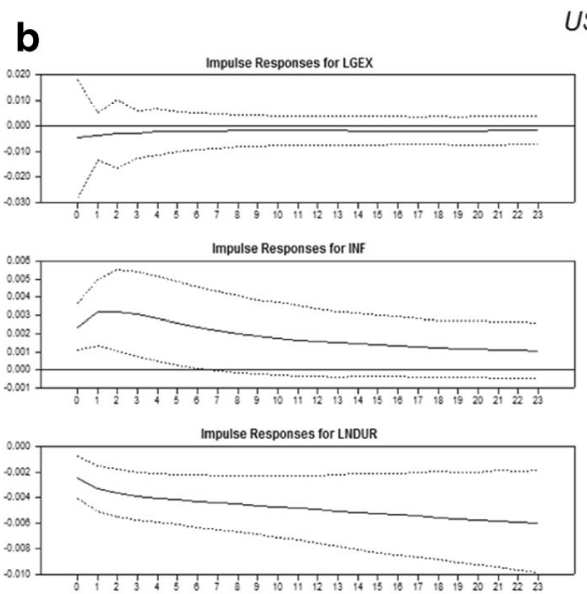

USA
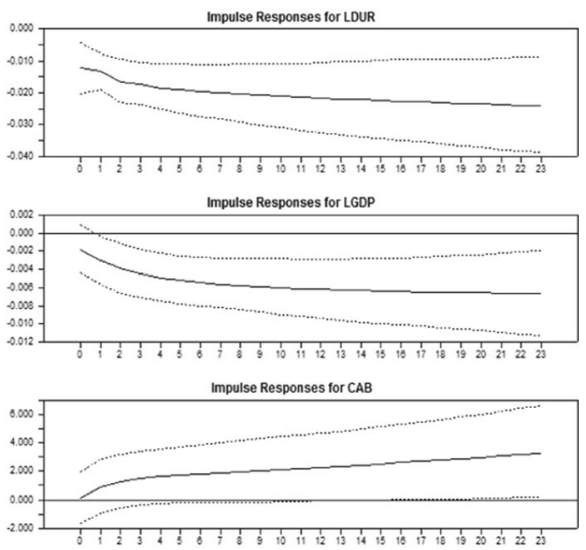

Impulse Responses with Pure-Sign Approach

Fig. 5 a US: Impulse responses of Fiscal Shocks from Sign-VAR. b US: Impulse responses of other Inflationary Shocks from Sign-VAR

first step, we randomly draw from the posterior distributions of the matrix of reduced form VAR coefficients, the variance covariance matrix of the error term, $\Sigma$. The usual structural VAR approach assumes that the error terms, $u_{t}$, are related to structural macroeconomic shocks, $\varepsilon_{t}$, via a matrix $A$, hence $u_{t}=A \varepsilon_{t}$. The identification approach here is to represent the one-step ahead prediction errors into economically meaningful or fundamental shocks that there are $n$ fundamental shocks which are mutually orthogonal and normalised to be of variance one. Hence, $\Sigma=E\left[u_{t}, u_{t}^{\prime}\right]=A E\left[\varepsilon_{t} \varepsilon_{t}^{\prime}\right] A^{\prime}=A A^{\prime}$, where this equation can be described as the Cholesky decomposition of $\Sigma$.

Given this restriction, Uhlig (2005) identification method searches over the space of possible impulse vectors, $A_{i} \varepsilon^{i}$ to find those impulse responses that agree with standard theory. The aim is to find an impulse vector, $a$, where $a \in \mathfrak{R}^{n}$, iif there is some matrix $A$, such that $A A^{\prime}=\Sigma$, where $A=\left[a_{1}, \ldots, a_{n}\right]$, so that $a$ is a column vector of $A$. As a result, 
a
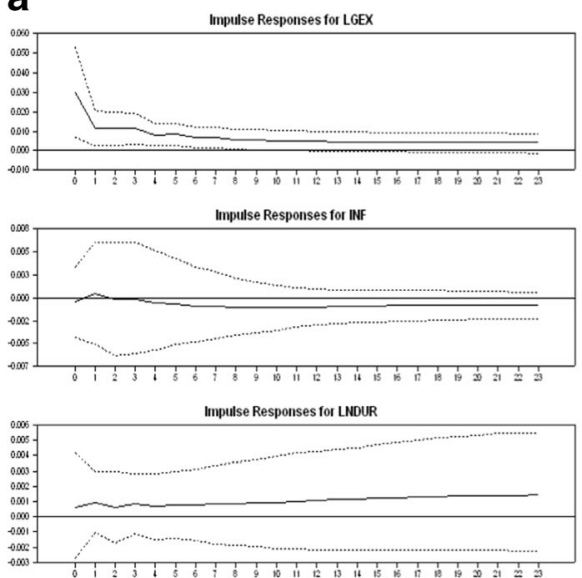

Impulse Responses with Pure-Sign Approach

b
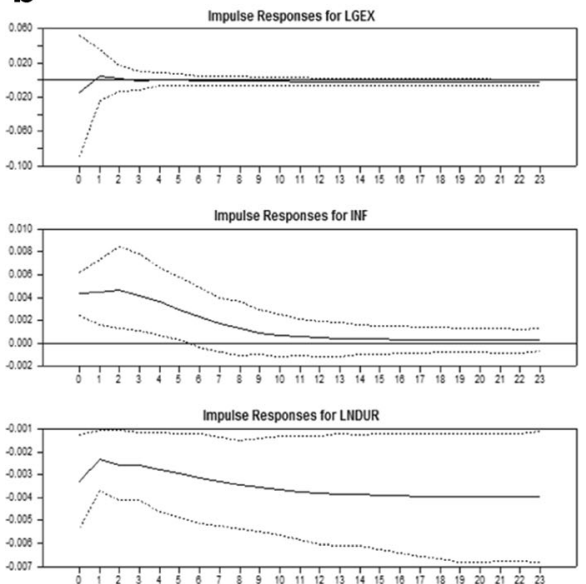

UK

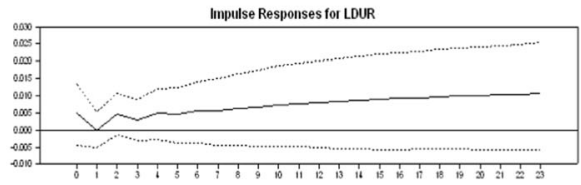

Impulse Responses for LGDP

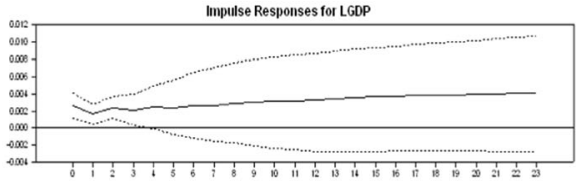

Impulse Responses for $C A B$

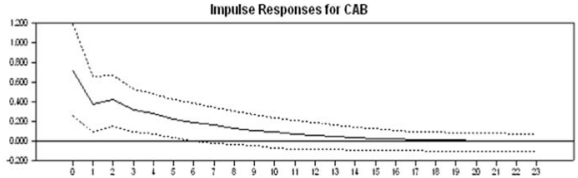

UK
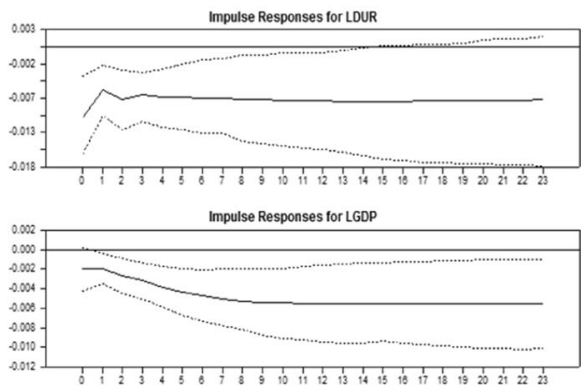

Impulse Responses for CAB

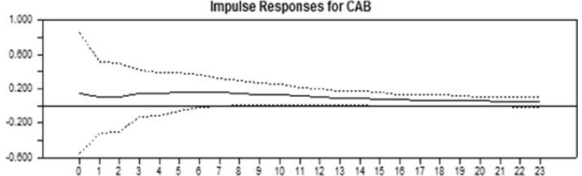

Impulse Responses with Pure-Sign Approach

Fig. 6 a UK: Impulse responses of Fiscal Shocks from Sign-VAR. b UK: Impulse responses of other inflationary Shocks from Sign-VAR

$a$, is an impulse vector if and only if there is an $n$-dimensional vector $\alpha$ of unit length so that $a=A^{\prime} \alpha$ and hence $\Sigma=A A^{\prime}=\sum_{i=1}^{n} a_{i} a_{i}^{\prime}$. Once the impulse vector $a$ has been appropriated, the impulse response is calculated as $\varepsilon_{a}(k)=\sum_{i=1}^{n} \alpha_{i} \varepsilon_{i}(k)$, where $\varepsilon_{i}(k) \in$ $\mathfrak{R}^{n}$ is the vector response at horizon $k$ to the $i$ th shock in a Cholesky decomposition of $\Sigma$ (Uhlig, 2005). This way, we obtain a range of impulse responses that are compatible with the sign restrictions.

The Uhlig procedure uses sign restrictions as obtained from the theoretical model in the previous section, not only upon impact, but for a few periods after 
a
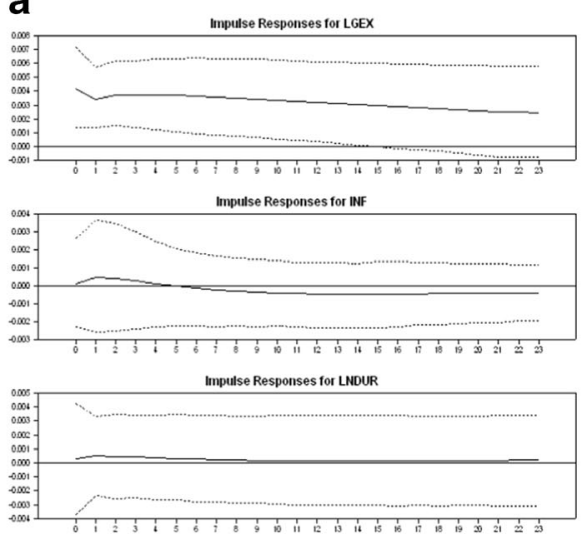

Impulse Responses with Pure-Sign Approach
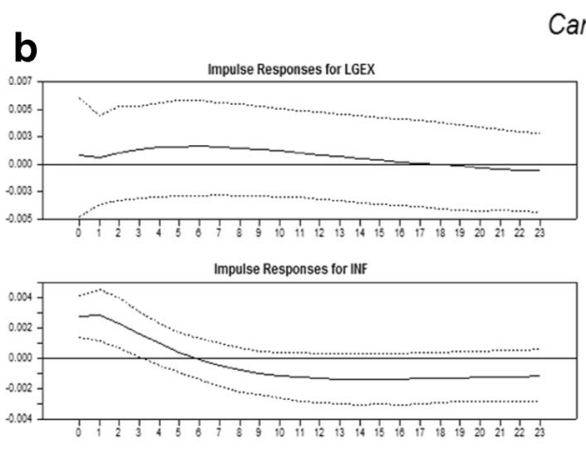

Impulse Responses for LNDUR

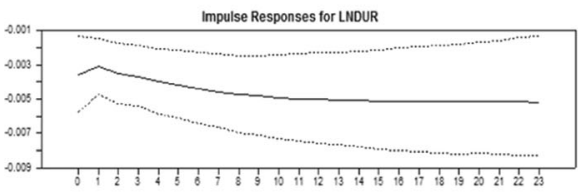

Canada
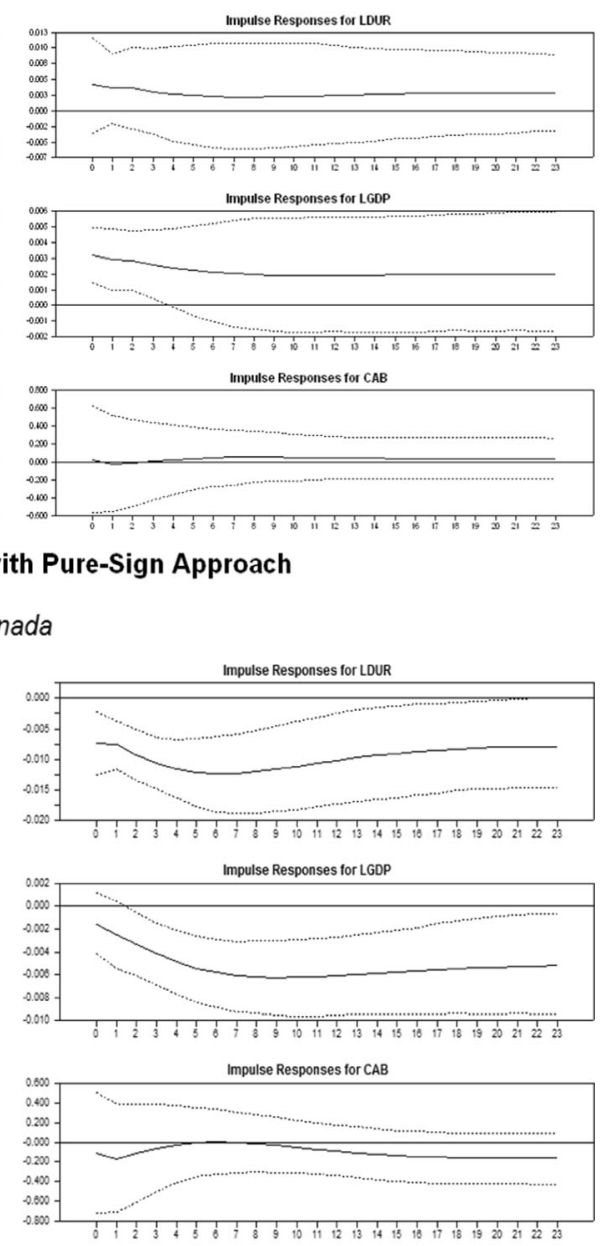

Impulse Responses with Pure-Sign Approach

Fig. 7 a Canada: Impulse responses of Fiscal Shocks from Sign-VAR. b Canada: Impulse responses of other inflationary Shocks from Sign-VAR

the shock's impact, which are shown in the impulse responses in Figs. 5, 6, 7, 8,9 , and 10 . The sign restrictions imposed are same as the sign effects derived in the theoretical model as follows:

Exhibit 1: Identifying Sign Restrictions

\begin{tabular}{lllllll}
\hline & LGEX & INF & LNDUR & LDUR & LGDP & CAB \\
Fiscal Shock (an increase in real government expenditure) & + & $?$ & $?$ & $?$ & + & $?$ \\
Positive Inflationary Shock & $?$ & + & - & - & - & $?$ \\
\hline
\end{tabular}

A positive inflation (INF) shock reduces the durable (LDUR) and non-durable (LNDUR) expenditures, and reduces the level of output (LGDP) and thereby increases 
USA
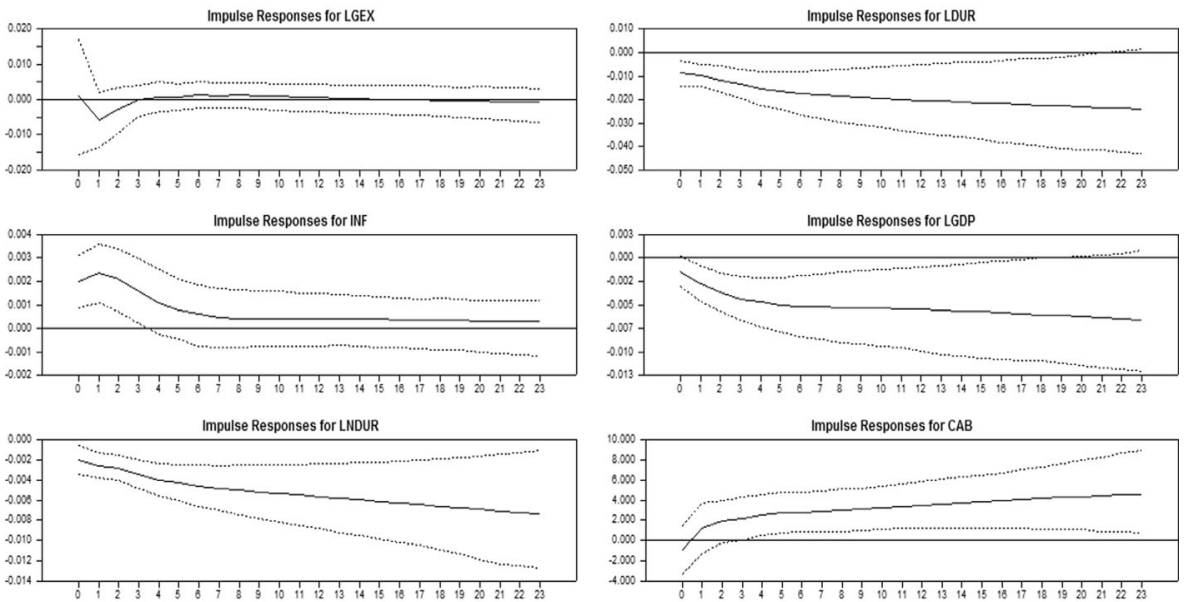

\section{Impulse Responses with Pure-Sign Approach}

Fig. 8 Impulse Responses of other inflationary shocks for USA during the post-1990 period

the current account balance $(\mathrm{CAB})$. No restriction however is placed on current account balance, since we do not want to prejudge the result because both domestic demand and external demand will influence the current account response. Fiscal policy shock is identified as an increase in government expenditure that will lead to an increase in output. We do not pre-judge the inflation outcome from a fiscal shock as inflation can either go up or down depending on whether real effect dominates the nominal effect. In order to unambiguously identify an exogenous fiscal shock from other inflationary shocks, it is quite clear from exhibit 1 that while a positive fiscal spending shock

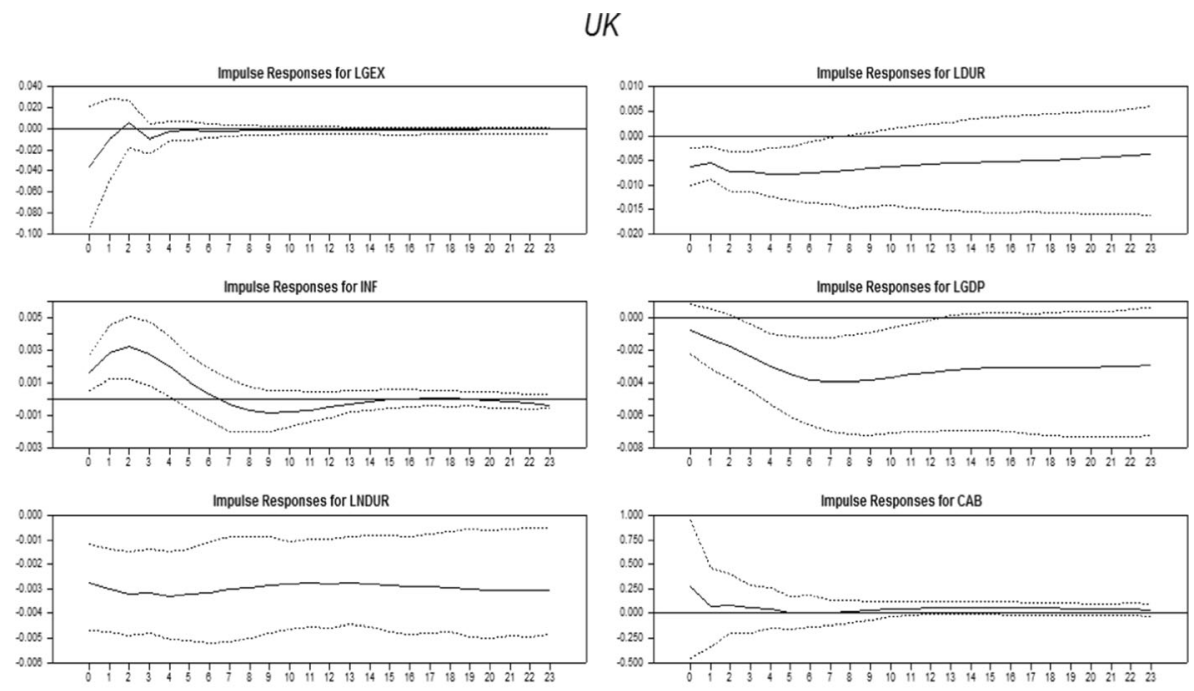

\section{Impulse Responses with Pure-Sign Approach}

Fig. 9 Impulse Responses of other inflationary shocks for UK during the post-1990 period 
Canada
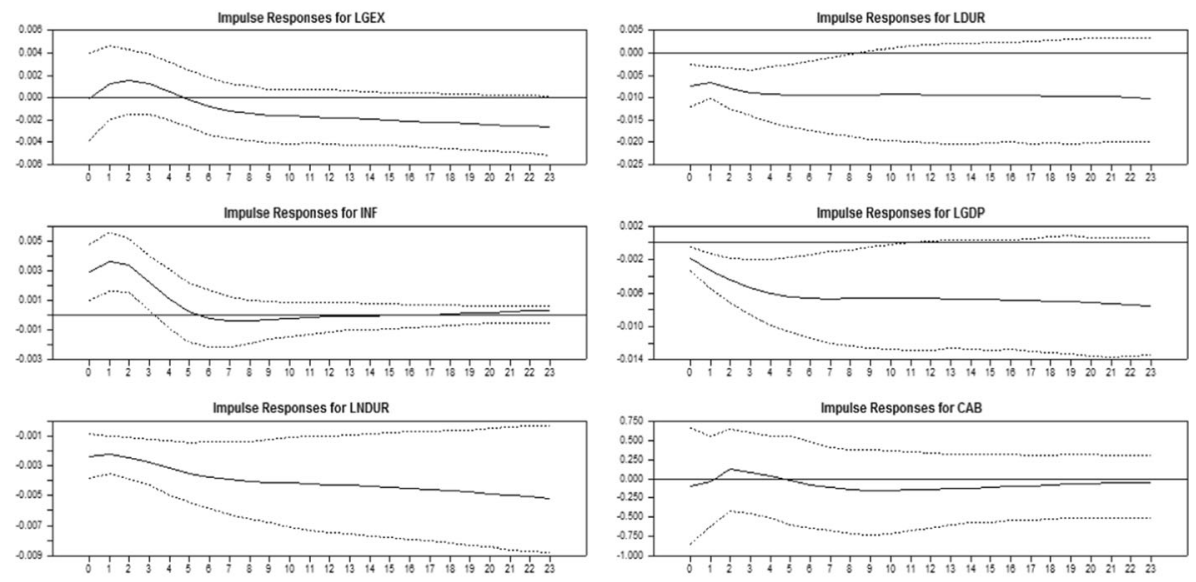

Impulse Responses with Pure-Sign Approach

Fig. 10 Impulse Responses of other inflationary shocks for Canada during the post-1990 period

increases economic activity, an inflationary shock reduces output, thereby disentangling their relative effects. These restrictions seem reasonable in the light of the earlier impulse responses. We keep those impulse vectors whose impulse response functions satisfy the Sign-Restrictions and discard the others. Further, having first identified the impact of fiscal shocks in a sign-VAR setting, we then carry out the impact of other inflationary shocks on real variables including the real current account balance. The responses in Figs. 5-10 satisfy the sign restrictions for $k=1, \ldots, K$ quarters. The responses of durables and non-durables have been restricted not to be positive, and the current account and inflation not to be negative for the first 2 quarters, following the shock. The error bands are illustrated as the dotted lines above and below the response line (the thick line), which are composed of the 16th, 84th and median percentiles of the impulse responses for each shock, from a sample of 1000 draws from the posterior. The dotted lines indicate the slope of the posterior distribution of the impulse responses as well as providing a confidence band for these responses.

Overall, all our empirical estimates suggest that in the long run inflation negatively affects consumption of durables and non-durables, and output, and we do find that such positive inflation shock contributes to a current account surplus via decline in demand. The results from fiscal shocks are in line with Perotti (2002), where the effect of spending shocks on output is much more muted with a smaller effect on price level. In the short-run however spending shock has positive effect on output, but the impact on inflation is somewhat neutral. For other inflationary shocks, our estimates suggest that households respond differently in terms of consumption of durables and non-durables in the short-run following inflationary shocks. It is intuitive to expect an excess-reaction for durable consumption, because the demand for durables may saturate more quickly than the demand for non-durables. Further, we examine whether the results remain robust in periods of high and low inflation rates. Sub-sample stability has been checked by estimating the Sign-VAR model for a smaller sample period (post-1990s) - a period of high productivity growth which most RBC type of models consider to identify the 


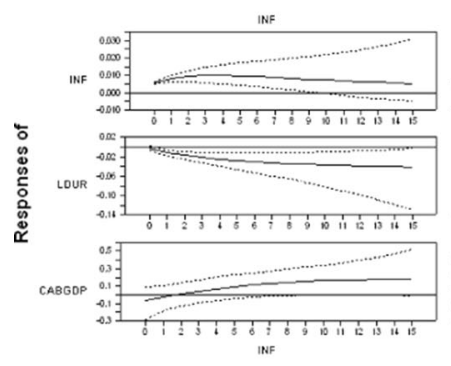

Impulse responses: 1985:01

(point estimates with $70 \%$ bands)
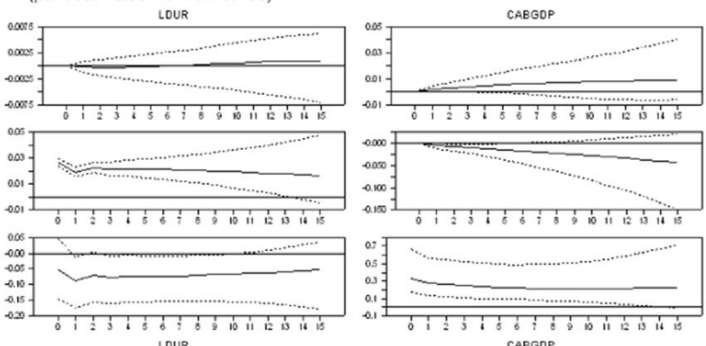

Shocks to

CABSDP
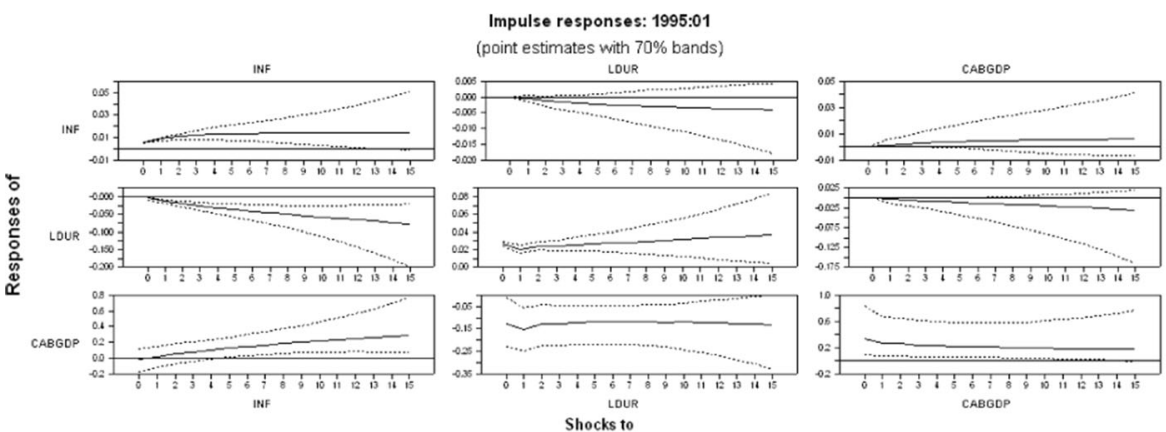

Shocks to

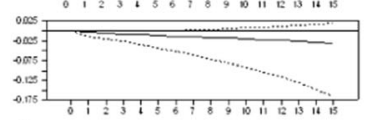

Impulse responses: 2004:01

(point estimates with $70 \%$ bands)
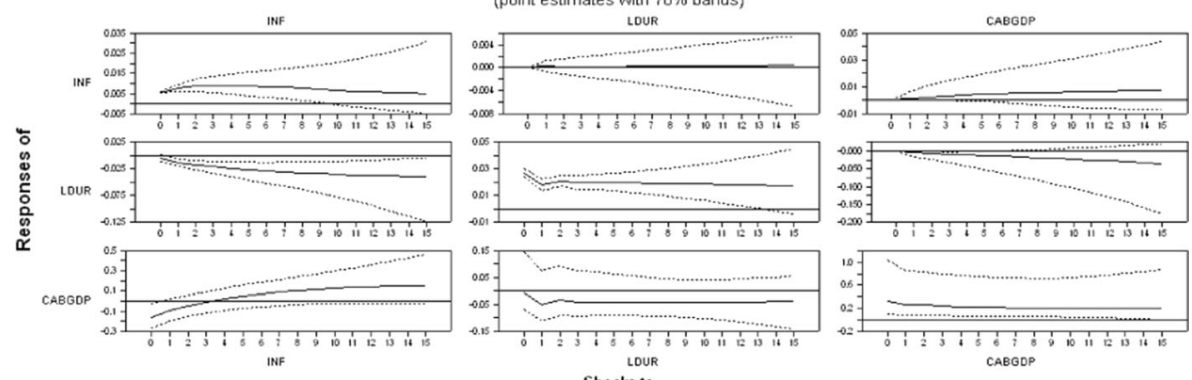
Shocks to

Fig. 11 USA - Impulse responses of Durable consumption and Current account balance to inflationary shocks in 1985:01, 1995:01 and 2004:01

role of technology shocks. Even within the great moderation period, our main nonneutrality result still holds (see Figs. 8-10).

\subsection{Time-Varying Structural VAR Approach}

As the above two approaches (both structural-VECM and sign-VAR) do not consider the time-varying properties of coefficients and the variance covariance matrix of the model's innovations, it clearly assumes that there is no structural break or regime shift in the joint-probability distribution across variables in the information set. So a timeinvariant VAR may not identify a possible regime shift (or an unconditional mean shift) that could be reflected through unanticipated shocks. In this sub-section, we therefore 


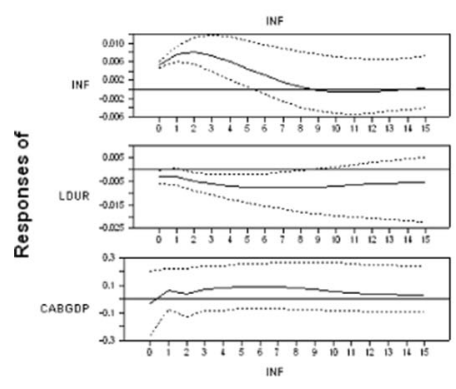

Impulse responses: 1985:01

(point estimates with $70 \%$ bands)
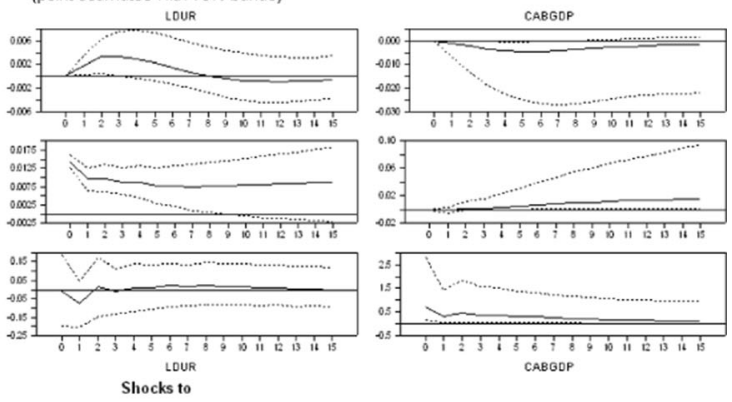

Impulse responses: 1995:01

(point estimates with $70 \%$ bands)
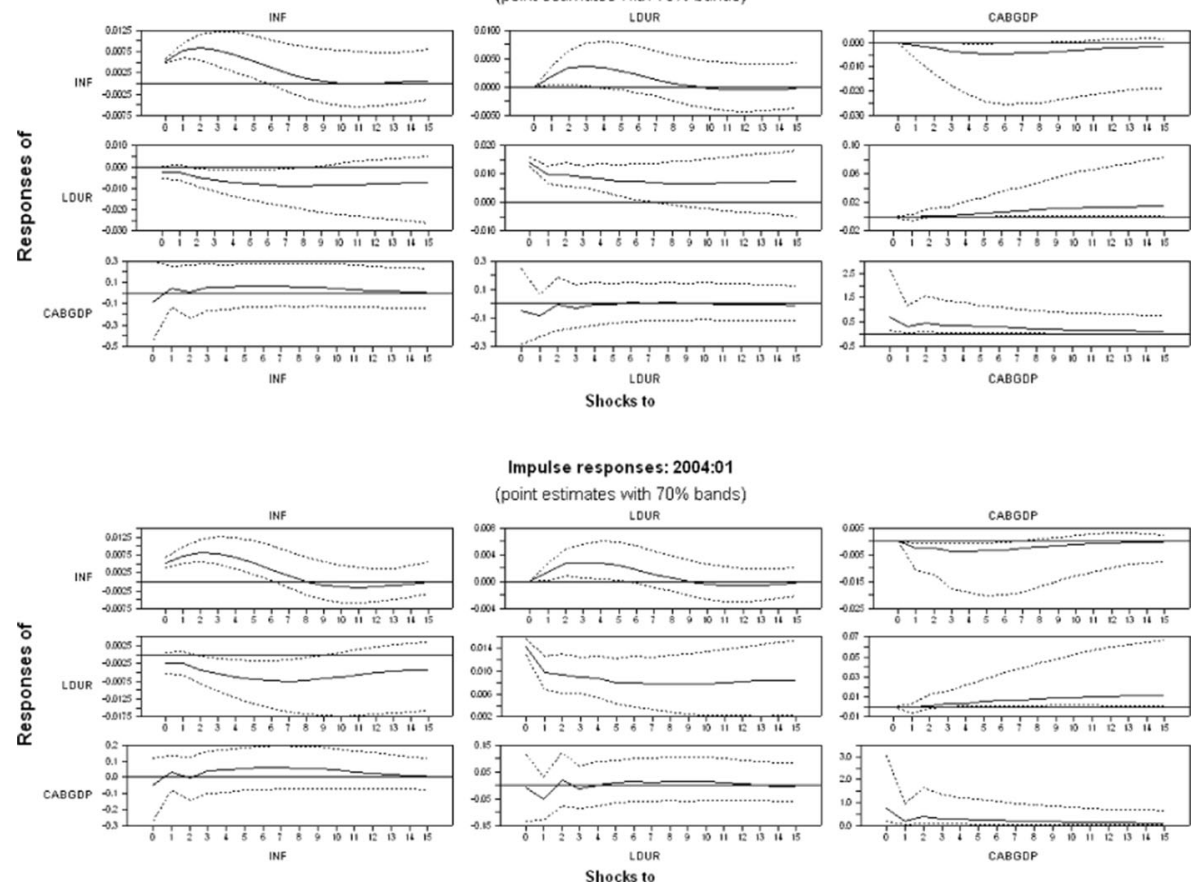

Fig. 12 UK - Impulse responses of Durable consumption and Current account balance to inflationary shocks in 1985:01, 1995:01 and 2004:01

address this concern in order to ascertain whether our key SVAR results have changed over time by estimating a time varying structural vector auto-regression (TV-SVAR), where the time variation is derived both from the coefficients and the variance covariance matrix of the model's innovations, by employing the methodology in Primiceri (2005). For details about Time-Varying SVAR, see Primiceri (2005).

Our TVSVAR includes inflation, real durable consumption, and real current account balance. We keep it as a 3-varible VAR, as it becomes computationally intensive with a large number of variables. Moreover our main variables of interest are durable consumption and current account balance. As one could see from the earlier impulse responses, the sign impact of the responses is same for durables and non-durables 

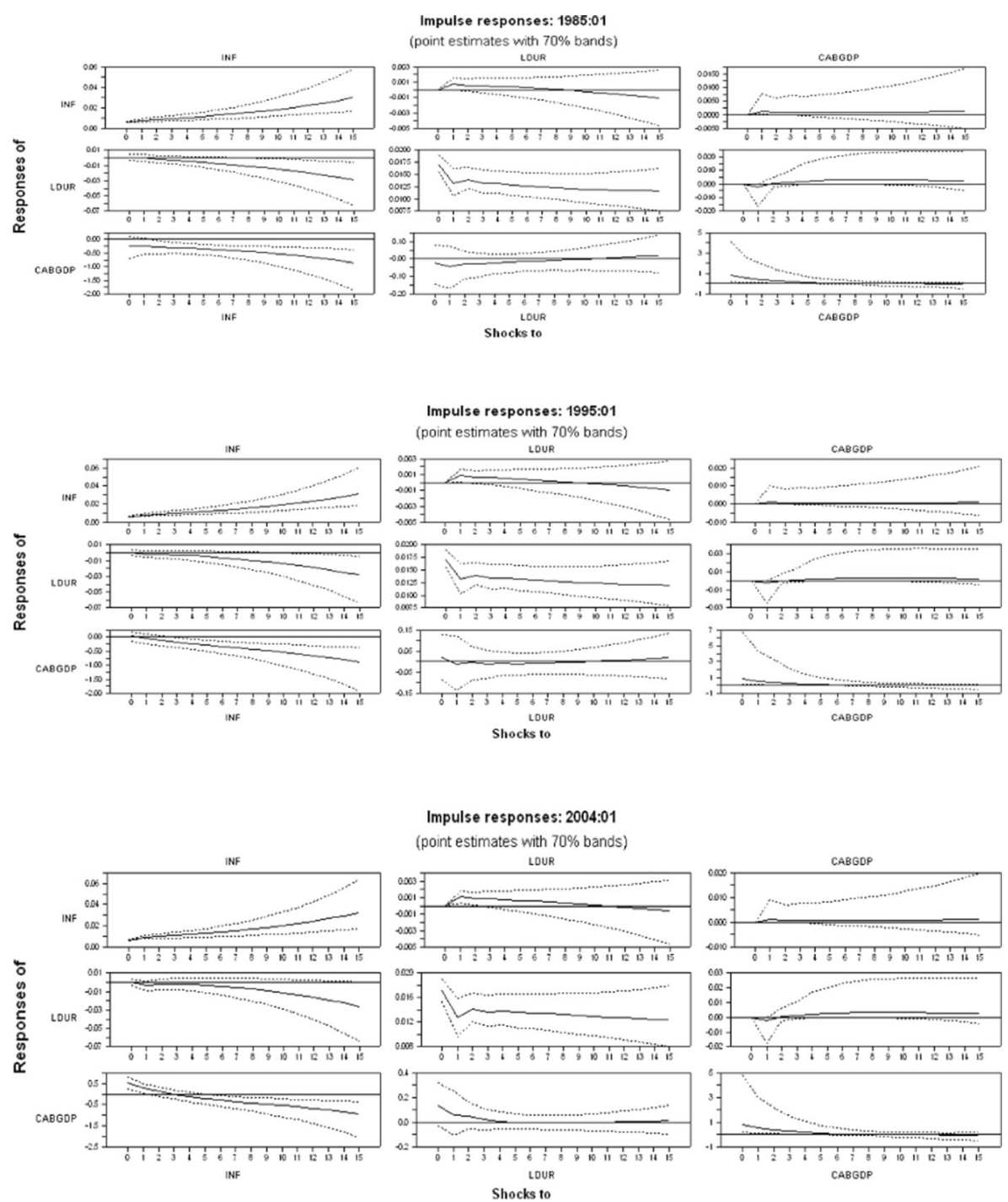

Fig. 13 Canada - Impulse responses of Durable consumption and Current account balance to inflationary shocks in 1985:01, 1995:01 and 2004:01

consumption and output. The variables are ordered from relatively exogenous to fully endogenous variables. This recursive order of variables is a strong restriction in conventional SVAR models. In Figs. 11, 12, and 13, we show Impulse Response Functions for three countries respectively for three different time points: 1985:Q1, 1995:Q1, and 2004:Q1.The results overall remain the same as before. The negative impact on durable consumption is still there for all countries and the positive impact on current account balance is quite clear for the US, and the UK in terms of median response, but not so for Canada as observed earlier partly due to the country running CA surpluses. The main result here remains consistent with the theoretical story that under a CIA constraint, higher inflation makes consumption goods (both durable and 
non-durable) more expensive relative to leisure. Higher leisure (or lower work effort) then reduces output. In the long run the decrease in consumption dominates the decrease in output, thereby producing a positive effect on the current account.

\section{Conclusion}

The main conclusions we reach in this study are as follows. Using both durable and non-durable goods explicitly in our model we show that inflationary monetary shocks turn out to be significant in changing consumption demand and thereby current account balance of the economy. In fact both at theoretical and empirical levels (using quarterly data from Canada, the UK and the USA and estimating correlations and impulse response functions), we are able to claim that inflation has a negative effect on consumption and output and positively influences the current account in the long run, even after having disentangled a fiscal surprise that might contribute to an inflationary shock. Through the use of impulse response functions, we examined the degree to which the consumption of durables versus non-durables differs to inflationary shocks in these three countries. Our results are generally robust across different econometric specifications. We also showed that durable consumption is more sensitive to inflationary shocks than non-durable consumption during initial periods. In other words, the disinflation in the last 25 years that we have observed in these countries may have contributed to a significant increase in durables consumption, which is then reflected in the deterioration of the current account.

Our findings have other interesting implications as well. The non-neutral and negative effects of inflation on real growth are crucial in many economic models in the asset pricing literature that propose a negative co-movement of stock prices and expected inflation. A negative response of long-run real growth to inflation produces positive inflation premium. This makes long-term nominal bonds risky, and is viewed as one of the leading economic explanations for a positive slope of the nominal term structure in the data. Though we do not deal with issues involving asset prices in this study, our findings seem very useful for asset pricing literature.

\section{Appendix I}

Incorporating all the optimality conditions and the flow budget constraints of the households and the government we obtain the following equations that capture the dynamics of the economy (assume $\alpha=1$ for simplification):

$$
\begin{gathered}
U_{1}\left(d_{t}+s_{t}, c_{t}\right)+\varphi_{t}-\left(1+r+\varepsilon_{t}\right) \mu_{t}=0, \\
U_{2}\left(d_{t}+s_{t}, c_{t}\right)=\mu_{t}\left(1+r+\varepsilon_{t}\right), \\
V^{\prime}(l)=\mu_{t} w_{t}
\end{gathered}
$$




$$
\dot{\varphi}_{t}=-U_{1}\left(d_{t}+s_{t}, c_{t}\right)+\varphi_{t}(\delta+\beta)
$$

$$
\dot{\mu}_{t}=\mu_{t}(\beta-r)
$$

$$
\dot{s}_{t}=d_{t}-\delta s_{t}
$$

$$
\dot{b}_{t}=1-l_{t}+r b_{t}-d_{t}-c_{t}-g_{t} .
$$

Here $\varphi$ is the shadow price of durable goods, and $\mu$ is the shadow price of assets. Since a small open economy takes the real interest rate as exogenous, clearly, for the existence of steady state in this model (5a) implies that $r=\beta$. This means that along the adjustment path, $\mu_{t}$ is always at its steady state level $\mu$. Also note that the equilibrium real wage is unity. Hence (3a) will be written as: $V^{\prime}(l)=\mu$,

We can solve equations (1a)-(3a) for $d, c$ and $l$ to obtain

$$
d=d(s, \varphi, \bar{\mu}, \varepsilon) ; c=c(\varphi, \bar{\mu}, \varepsilon) \text { and } l=l(\bar{\mu}) .
$$

First, we solve the dynamics involving the stock and shadow price of consumer durables. To derive the saddle path, we linearize (4a) and (6a) around the steady state. The system has saddle point stability and the saddle path is given by the following equations:

$$
s_{t}-\bar{s}=\left(s_{0}-\bar{S}\right) e^{-(1+\delta) t} ; \phi_{t}-\bar{\phi}=0
$$

The adjustment paths of durable and non-durable consumption and employment are given by

$$
d_{t}-\bar{d}=-\left(s_{0}-\bar{s}\right) e^{-(1+\delta) t} ; c_{t}-\bar{c}=0 \text { and } L_{t}-\bar{L}=0 .
$$

Next, consider the country's external adjustment along the perfect foresight path:

$$
\dot{b}_{t}=1-l_{t}+r b_{t}-d_{t}-c_{t}
$$

Linearizing this equation around the steady state we obtain

$$
\dot{b}_{t}=r\left(b_{t}-b\right)+\left(s_{0}-s\right) e^{-(1+\delta) t}
$$


The solution to this differential equation is

$$
b_{t}-\bar{b}=-\frac{1}{(1+r+\delta)}\left(s_{0}-\bar{s}\right) e^{-(1+\delta) t}
$$

To obtain the converging solution we have imposed the following condition (see also Mohsin (2006)):

$$
\left(b_{0}-\bar{b}\right)+\frac{1}{(1+r+\delta)}\left(s_{0}-\bar{s}\right)=0
$$

Equation (19a) could be described as a relationship between the stock of internationally traded bonds and the stock of consumer durables that must be satisfied to obey the intertemporal solvency condition.

Now to examine the steady state effects of an unanticipated permanent increase in the inflation rate, the following steady state effects are established:

$$
\begin{gathered}
\frac{d \bar{d}}{d \varepsilon}=-\frac{\delta \bar{\mu}\left[U_{12}(1+r+\delta)-U_{22}(r+\delta)\right]}{D}<0, \\
\frac{\overline{d s}}{d \varepsilon}=-\frac{\bar{\mu}\left[U_{12}(1+r+\delta)-U_{22}(r+\delta)\right]}{D}<0, \\
\frac{\overline{d c}}{d \varepsilon}=-\frac{\bar{\mu}\left[U_{12}(1+\delta)(r+\delta)-U_{11}(1+\delta)(1+r+\delta)\right]}{D}<0, \\
\frac{d \bar{L}}{d \varepsilon}=\frac{(20 \mathrm{a})}{\left(U_{11}(1+\delta)(1+r+\delta)-U_{12}(1+r+\delta)\left\{\frac{r}{1+r+\delta}+2 \delta+r\right\}+U_{22} r(r+\delta)\left(1+\frac{1}{D}\right)\right.} \\
\frac{d \bar{b}}{d \varepsilon}=\frac{1+r+\delta}{\bar{\mu}}<0 \\
\frac{(1+r+\delta)}{D}\left[U_{12}(1+r+\delta)-U_{22}(r+\delta)\right] \\
D
\end{gathered}
$$

where

$$
\begin{aligned}
D= & \left(U_{11} U_{22}-U_{12}^{2}\right)(1+\delta)(1+r+\delta)+V^{\prime \prime}(1+r+\delta) \\
& \left\{U_{11}(1+r+\delta)(1+\delta)-U_{12}\left(r+2 \delta(1+r+\delta)+U_{22}(r+\delta)(\delta+r /(1+r+\delta)\}>0 .\right.\right.
\end{aligned}
$$


The short-run overshooting of durable consumption and the gradual increase thereafter following inflationary shock can be verified if one differentiates (8a) with respect to $\varepsilon$ and evaluate at the short run and then compare it with (20a) to get the following:

$$
\begin{gathered}
\frac{d d(0)}{d \varepsilon}=d_{\varphi} \frac{d \bar{\varphi}}{d \varepsilon}+d_{\mu} \frac{d \bar{\mu}}{d \varepsilon}+d_{\varepsilon}<0 . \\
\frac{d \bar{d}}{d \varepsilon}-\frac{d d(0)}{d \varepsilon}=d_{s} \frac{d \bar{\varphi}}{d \varepsilon}=\frac{\bar{\mu}\left[U_{12}(1+r+\delta)-U_{22}(r+\delta)\right]}{D}>0 .
\end{gathered}
$$

Similarly the short-run decrease in the consumption of non-durables due to higher inflation could be established as follows:

$$
\frac{d c(0)}{d \varepsilon}=c_{\mu} \frac{d \bar{\mu}}{d \varepsilon}+c_{\varphi} \frac{d \bar{\varphi}}{d \varepsilon}+d_{\varepsilon}<0
$$

Compared to its long run effect in (22a), there is no overreaction in the consumption of non-durables. These results are very much consistent with our empirical results obtained through correlation coefficients and generalized impulse response functions. With higher inflation, as our theoretical model predicts, we must observe decrease in consumption of durable and non-durable goods in the short run. In the long run the economy must experience overall decrease in consumption of both goods, contributing to a lower level of output. But the net foreign asset position will improve. The estimated correlation coefficients with zero and up to ten lags in our sample countries clearly confirm the short run effects in consumption as suggested by our model. The impulse response functions over the longer horizon are able to track the effects of inflation. The empirical results are very supportive of the steady state effects as established in equations 20a-24a. Moreover, the overreaction of durable consumption compared to non-durable consumption is also verified.

Open Access This article is distributed under the terms of the Creative Commons Attribution 4.0 International License (http://creativecommons.org/licenses/by/4.0/), which permits unrestricted use, distribution, and reproduction in any medium, provided you give appropriate credit to the original author(s) and the source, provide a link to the Creative Commons license, and indicate if changes were made.

\section{References}

Abel AB (1985) Dynamic behaviour of capital accumulation in a cash-in-advance model. J Monet Econ 16: $55-71$

Backus D, Driffill J (1985) Inflation and reputation. Am Econ Rev:530-538

Bansal R, Shaliastovich I (2013) A long-run risks explanation of predictability puzzles in bond and currency markets. Rev Financ Stud 26(1):1-33

Calvo GA (1987) Balance of payment crisis in a cash-in-advance economy. Journal of Money Credit and Banking 19:19-32 
Calvo GA, Vegh CA (1995) Fighting inflation with high interest rates: the small-open economy case under flexible prices. Journal of Money Credit and Banking 27:49-66

De Gregorio J, Guidotti P, Vegh C (1998) Inflation stabilisation and the consumption of durable goods. Econ J 108(446):105-131

Dunn KB, Singleton KJ (1986) Modelling the term structure of interest rates under non-reparability utility and durability of goods. J Financ Econ 17:27-55

Eraker B., Shaliastovich I., and Wang W., 2014, Durable goods, inflation risk, and equilibrium asset prices, Working Paper. http://finance.wharton.upenn.edu/ ishal/papers/ESW_dur.pdf.

Erceg JC, Levin AT (2006) Optimal monetary policy with durable consumption goods. J Monet Econ 53: 1341-1359

Ferson WE, Constantinides GM (1991) Habit persistence and durability in aggregate consumption: empirical tests. J Financ Econ 29:199-240

Fisher, J. A. (2001): A real explanation for heterogeneous investment dynamics. Federal Reserve Bank of Chicago WP-01-14. doi:10.2139/ssrn.294940

Hasseltoft H (2012) Stocks, bonds and long-run consumption risks. J Financ Quant Anal 47:309-332

Heaton J (1995) An empirical investigation of asset pricing with temporally dependent preference specifications. Econometrica 61:353-385

Iscan TB (2002) Present value tests of the current account with durables consumption. J Int Money Financ 21(3):385-412

Johansen S (1988) Statistical analysis of Cointegrating vectors. J Econ Dyn Control 12:231-254

Kydland F, Prescott E (1977) Rules rather than discretion: the inconsistency of optimal plans. J Polit Econ: 473-492

Madsen, J.B. (2001): Disinflation, real income uncertainty and the demand for consumer durables in a meanvariance model of portfolio selection. The ManchesterSchool, March, 69 (2): 179-196.

Mallick SK, Mohsin M (2010) On the real effects of inflation in open economies: theory and empirics. Empir Econ 39(3):643-673

Mankiw GN (1987) Government purchases and real interest rates. J Polit Econ 95:407-419

Mishkin FS (2000) Inflation targeting in emerging-market countries. Am Econ Rev Pap Proc 90:105-109

Mansoorian A, Mohsin M (2006) On the employment, investment and current account effects of inflation. J Int Econ 70:296-313

Mohsin M (2006) Durability in consumption and the dynamics of the current account. J Econ Dyn Control 30: $143-162$

Perotti, R. (2002),Estimating the effects of fiscal policy in OECD countries, ECB Working Paper No. 168: ECB.

Piazzesi M, Schneider M (2006) Equilibrium yield curves. NBER Macroecon Annu 21:389-472

Primiceri GE (2005) Time varying structural vector Autoregressions and monetary policy. Review of Economic Studies 72(3):821-852

Stockman AC (1981) Anticipated inflation and the capital stock in a cash-in-advance economy. Journal of Monetary Economics 8:387-393

Uhlig H (2005) What are the effects of monetary policy on output? Results from an agnostic identification procedure. J Monet Econ 52(2):381-419

Walsh C (1995) Optimal contracts for central bankers. Am Econ Rev 85(March):150-167

Yang W (2011) Long-run risk in durable consumption. J Financ Econ 102:45-61

Zivot E, Andrews K (1992) Further evidence on the great crash, the oil price shock, and the unit root hypothesis. J Bus Econ Stat 10(3):251-70 